\title{
EL ESTUDIO DE LA LITERATURA A TRAVES DE LA HISTORIA
}

\author{
Manuel Picado
}

La reflexión sobre la literatura es tan antigua como la misma obra literaria. Esto se repite con frecuencia $y$ parece tener el carácter de lo evidente. Sin embargo, a través de la historia no se ha entendido por literatura el mismo objeto, ni se ha adoptado la misma actitud en la búsqueda del conocimiento sobre lo literario. Por una parte, con mayor o menor fuerza se ha negado la posibilidad de un conocimiento riguroso $y$ sistemático del fenómeno literario; por otra, con fundamento o sin él se han sucedido teorías y sistemas de aspiración científica implícita o declarada. Unas veces se ha pretendido subordinar el estudio de la literatura al conocimiento de diferentes sectores culturales; otras, se ha proclamado la necesidad de abordar lo poético en su especificidad.

Todas las contingencias de la teoría de la literatura interesan no solo por ser historia del pensamiento humano, sino también por los vislumbres alcanzados y los caminos, erróneos o acertados, abiertos al conocimiento. Aparte de eso, hay que destacar que no obstante la diversidad de caminos y opiniones se observa una cierta continuidad en la reflexión. Valga mencionar la recuperación de la retórica que intenta la corriente estructuralista, una dirección de estudio que cuenta con plena vigencia en la actualidad. También se observa que con mucha frecuencia una etapa de estudio suele arrastrar diversos supuestos de carácter tópico que pertenecen a etapas que parecían ya superadas. Es este el caso de la famosa dicotomía forma-fondo o la noción de literatura como lenguaje figurado, que están presentes en concepciones a primera vista muy alejadas.

Gustav Siebenmann en su libro Hacia una crítica cientifica, basándose en la división de los tres poderes (legislativo, judicial y ejecutivo), propone un esquema del desarrollo histórico de la teoría de la literatura. Si bien este esquema puede ser discutible como tal, parece útil para intentar una ojeada histórica que permite avanzar hasta el romanticismo y pleno siglo diecinueve. Con algunas modificaciones y ampliaciones, el presente esbozo histórico se acogerá a la idea de Siebenmann.

Los estudios sobre la literatura nacen como una actividad legislativa. Se observa un cúmulo de obras, se establecen las leyes que las organizan y se proponen como normas. Los monumentos de este modo de reflexionar los brinda la Antigüedad Clásica: la Poética, de Aristóteles y el Arte Poética de 
Horacio, que constituyen dos de las obras más señaladas al efecto. No por eso hay que dejar de citar en Grecia, las preocupaciones literarias diseminadas en las obras filosóficas de Platón y en la creación del dramaturgo Aristófanes. En Roma es indispensable citar las obras de Cicerón y Quintiliano.

La línea inaugurada por Aristóteles llega hasta el siglo XVIII y en su forma ortodoxa se refugia hoy en manuales de segundo orden. Por ejemplo, el programa aristotélico de la poética comprendía, grosso modo, una teoría general del arte, una concepción de los géneros literarios y un desarrollo de cada uno de estos. (Recuérdese que si bien la Poética que se conoce hoy toca casi exclusivamente el drama, hay elementos de juicio para creer que Aristóteles desarrolló sus nociones de lírica y narrativa en manuscritos lamentablemente perdidos). $\mathrm{Si}$ se observa el programa de Aristóteles, tal como se ha expuesto, su huella parece evidente en los manuales que usaron y usan muchas generaciones; en ellos se partía de ciertos conceptos de lo bello para terminar postulando la existencia de tales y cuales géneros con sus respectivas características.

Desde una mentalidad moderna, la actitud legislativa exhibe aspectos negativos y positivos. Es positiva cuando se propone lograr un conocimiento sistemático y riguroso de lo literario; también lo es cuando se interesa por la observación e inicia un cierto atomismo que lleva a determinar unidades y relaciones constituyentes del objeto poético.

Es negativa en cuanto que al establecer cánones partiendo de las obras de un período histórico, produce un conjunto teórico incapaz de contemplar las nuevas manifestaciones del fenómeno literario. El matiz legislativo -muchas veces ignorado por autores y lectores- de algunos enfoques de teoría de la literatura, explica las dificultades que se presentan a la hora de estudiar ciertos temas, puesto que se establecen determinaciones que si bien pueden responder a cierta época, no concuerdan con otra. $\mathrm{Mu}$ chos habrán experimentado estos problemas, por ejemplo a la hora de enseñar el tema de los géneros literarios. Se dice que los géneros literarios son cierto número de manifestaciones literarias y de inmediato el maestro y el estudiante inteligentes observan que hay fenómenos poéticos que difícilmente encuadran en los marcos teóricos trazados.

$\mathrm{La}$ actividad legislativa recibió el nombre genérico de poética o arte poética. Esto hizo que el término se cargara de connotaciones prescriptivas aún vigentes. Por eso en la actualidad, cuando se quiere usar el vocablo con acepción científica, tal como en el caso de Wolfgang Kayser o Tzvetan Todorov, velada o declaradamente se procede a renovarlo.

Existe consenso de que la Edad Media no ofrece preocupaciones teóricas con respecto a la literatura. Esto se evidencia en el hecho de que no hay mayor interés por la unidad terminológica. El objetivo predominante pareciera ser el jerarquizar de acuerdo con criterios éticos y didácticos. La distinción entre literatura de tono mayor y de tono menor, que con frecuencia suele hallarse es escritos periodísticos y de diverso carácter, viene del medioevo.

Con el Renacimiento adviene la actitud judicial. Al revalorizarse la antigüedad grecolatina, se toma la legislación clásica y se juzga de acuerdo con ella. La imagen literaria de esta actitud la encarna el escrutinio de los libros en el capítulo sexto de la primera parte del Quijote.

El Renacimiento también supone una tensión. Al observar la realidad literaria es evidente el hecho de que han surgido nuevas manifestaciones cuya existencia no estaba prevista en las poéticas clásicas. Es por esto que la actividad legislativa también va a dar sus frutos. Para dar cabida a nuevos fenómenos literarios prolife ran las poéticas. Citemos solo algunos casos: En Francia, Boileu con su Art Poétique (1674); en Italia, Scaligero con Poetices libri septem (1561); en Inglaterra, Dryden con su Essay on dramatic poesy (1688); y en España, Lope de Vega con el Arte nuevo de escribir comedias (1609) y Luzán con su Poética (1737).

En algunos casos se quiere ser compulsivo respecto a la praxis artística. $O$ sea que las poéticas rigen para el estudio y la creación literaria, lo cual indica que no se distinguen los campos del artista y del estudioso.

El siglo XVIII representa el apogeo y caída de la poética y la retórica entendidas como cuerpo de normas. La compulsión 
modélica, rasgo característico del neoclasicismo, con los extremos que alcanza contribuye al descrédito de la poética.

El romanticismo da paso a lo que Siebenmann llama la actitud ejecutiva. Según esto, el artista es el único autorizado para hablar del arte y la crítica o estudio literario son un género al igual que la novela o la poesía. Aquí se origina la "terrible superstición estética", según la cual el estudioso de la literatura tenía que ser un poeta y la crítica una obra de arte creada al meditar sobre otra. Obviamente con esto se descarta la posibilidad de un conocimiento sistemático y objetivo de la literatura. Valga la oportunidad para señalar que esta idea tiene todavía mucho arraigo; de otro modo no se explicaría el grado de verdad que normalmente se concede al testimonio de los escritores. Por otra parte, el razonamiento puede fácilmente reducirse al absurdo puesto que, de acuerdo con él, para ser médico -por ejemplo- habría que padecer las enfermedades.

En esta actitud ejecutiva del romanticismo está el antecedente de la crítica impresionista cuyo maestro es Azorín y de la crítica creadora de Paul Valery y T.S. Elliot, dos movimientos muy importantes en nuestro siglo. Asimismo, aquí suele verse un antecedente de la posición esteticista del italiano Benedeto Croce, quien tanto ha influido en movimientos de envergadura tales como la estilística, especialmente en su versión de la escuela española de Amado y Dámaso Alonso.

La teoría literaria del siglo XX tiene una gran deuda con el siglo XVIII y con el romanticismo. Al igual que toda la tradición, el Siglo de las Luces aceptaba la fórmula horaciana de que las funciones de la literatura eran "prodesse er delectare" (ser de provecho y deleitar). Sin embargo, observa otras facetas de la experiencia literaria que escapan al deleite estético y a la comprensión intelectual. El siglo XVIII ve la obra como vivencia de lo individual y al mismo tiempo de lo histórico. La obra es expresión de un creador, pero también documento de una época. Junto a la fuerza creadora del poeta, aparecen como coadyuvantes, el espíritu de la época y del pueblo. Esta inquietud culmina con el movimiento de los román- ticos. De este modo, en el siglo XIX, a la par de la valoración estética y normativa surge el estudio histórico y la idea de que para la comprensión absoluta de las obras es necesario conocer su contexto histórico. Los románticos en su interés por lo popular y autóctono desarrollan el estudio de las literaturas nacionales y la tradición oral folklórica. Recuérdese el caso de los hermanos Grimm.

Un aporte innegable del romanticismo es que en su interés por lo popular y nacional, desarrollan la inquietud por las relaciones entre la sociedad y la literatura, problema que mueve actualmente a una serie de investigadores entre los cuales destaca Lucien Goldmann con su método estructuralista genérico. Según Jacques Leenhard, en la obra de Madame de Staël (Sobre la literatura considerada en sus relaciones con las instituciones sociales), está ya el proyecto cabal de una sociología de la literatura.

El siglo XIX contempla, por una parte, el descrédito de toda actividad normativa, $y$, por otra, el auge de las ciencias naturales y la autoconciencia de la actividad científica. El espíritu dominante de la época impregna también a los estudios literarios y estos se propondrán la búsqueda de la verdad. El acercamiento de los estudios literarios a la ciencia ocurre bajo el signo del naturalismo (Charles Darwin) y el positivismo que acepta como único método el experimental.

De este modo el siglo XIX va a plantear un problema al que aún hoy estamos abocados: la aplicación estricta de un concepto de ciencia a los objetos estético-literarios. Siguiendo las pautas de la época y al igual que la lingüística, la teoría literaria se hace casi exclusivamente diacrónica. Incluso en muchas ocasiones, historia literaria se convierte en sinónimo de estudio literario. Esto aún está vigente en muchos libros que bajo el título de historia de la literatura pretenden referirse a los aspectos generales de la estética literaria. A su vez hay que destacar que dentro de este enfoque historicista, las nociones del escritor y del medio se revelan como predominantes.

Según Wolfgang Kayser, el positivismo decimonónico limita su atención a tres sectores:

a) Edición crítica de los textos. $\mathrm{Se}$ 
trata de filología en sentido estricto, campo en el cual la actividad científica nos ha legado un resultado inapreciable.

b) Fuentes y genésis de las obras.

c) Estudio minucioso de las circunstancias del escritor.

Basta contemplar los programas de literatura de muchos cursos universitarios y ciertos programas de escuela secundaria, para advertir la influencia del programa propio del siglo XIX.

Para terminar no está demás recordar que la intención de estas líneas fue la de trazar un recorrido, necesariamente esque- mático, del estudio de la literatura hasta el siglo XIX. El interés fue mostrar la antigüedad de la preocupación por la literatura y la innegable continuidad que existe en la reflexión en torno al fenómeno poético. Es necesario tomar conciencia de la tradición que nos precede con el ánimo de superar sus limitaciones, aprovechar sus atisbos y ubicarse en la reflexión de quienes se han preguntado por la literatura.

Para superar todos los defectos de una panorámica como la que se ha intentado, el lector puede remitirse a la bibliografía.

\section{OBRAS CONSULTADAS}

Bonet, Carmelo. La critica literaria. Ed. Nova: Buenos Aires, 1967.

De Aguiar e Silva, Vítor Ml. Teoria de la Literatura. Ed. Gredos: Madrid, 1972.

Goldmann, Lucien y otros. Sociología de la creación literaria. Eds. Nueva Visión: Buenos Aires, 1968.

Kayser, Wolfgang. Interpretación y análisis de la obra literaria. Gredos: Madrid, 1968.

Montes, Hugo. De Platón a Neruda. Publicaciones de la Universidad de Costa Rica. 1973.
Siebenmann, Gustav. Hacia una critica científica. (Análisis de la problemática relación entre literatura y ciencia). Eds. Diálogo: Paraguay, s.f.

Wellek, René. Historia de la critica moderna. "La segunda mitad del siglo XVIII, vol. I, Ed. Gredos: Madrid, 1969.

- Historia de la crítica moderna. "El Romanticismo", vol II, Ed. Gredos: Madrid, 1962.

. Historia de la crítica moderna. "Los años de transición”, vol. III, Ed. Gredos: Madrid, 1972. 